\title{
Evaluating citizens' willingness to uptake a MaaS tool for metropolitan multimodal trips
}

\author{
Andres Monzon \\ TRANSyT-UPM \\ Madrid, Spain \\ andres.monzon@upm.es
}

\author{
Iria Lopez-Carreiro \\ TRANSyT-UPM \\ Madrid, Spain \\ iria.lopez@upm.es
}

\author{
Elena Lopez \\ TRANSyT \\ Madrid, Spain \\ elena.lopez@gmail.com
}

\begin{abstract}
The paper presents some results of the EU project KLIMATe, funded by the EIT Climate. KLIMATe explores the market potential for implementing a Mobility as a Service (MaaS) travel-assistance application in the metropolitan area of Madrid (Spain). This tool would allow travellers to obtain personalised multimodal recommendations on-demand for cleaner urban mobility choices. Thus, it would facilitate the transition towards more liveable, zero-carbon and resilient cities. We performed an extensive online survey of transportation choices in Madrid. The questionnaire was focused on four aspects: (i) socio-demographic characteristics, (ii) personal traits, (iii) personal attitudes and (iv) travel habits. Our findings provide researchers and practitioners with a better understanding of the users' willingness to adopt travel-planning applications, allowing to identify potential elements to be considered for the successful implementation of these technologies.
\end{abstract}

Keywords-Mobility as a Service, Willingness to adopt, Usercentric approach.

\section{INTRODUCTION}

The paper presents some results of the EU project KLIMATe, funded by the EIT Climate. KLIMATe explores the market potential for implementing a MaaS travelassistance application in the metropolitan area of Madrid (Spain). This tool would allow travellers to obtain personalised multimodal recommendations on-demand for cleaner urban mobility choices.

Urban mobility systems are going through a significant transition that will affect the future of our cities (Jin et al., 2018). Traditional mobility services are being substituted by emerging tailor-made mobility options, such as ride-sharing or ride-hailing services. At the same time, the digital age brings new relevant opportunities that transform urban lifestyles and mobility requirements. At present, Information and Communication Technologies (ICTs) are in almost every aspect of our daily lives.

Within this context, the notion of MaaS arose in 2014 to revolutionize the urban mobility paradigm. Literature sustains that MaaS is mainly based on digitalisation and a user-centric approach. However, until now, it has no single definition. Diverse authors propose the same essential idea, which is the conception of mobility as a range of services available on demand (Hietanen, 2014; and Kamargianni et al., 2016). MaaS introduces an innovative mobility distribution model that deliver users' transport needs through a service provider's unique digital interface (Polis, 2017). Its main goal is to offer travellers flexible, reliable, personalized and seamless doorto-door mobility services.

In accordance with a comprehensive literature review, MaaS definitions share the following basic ideas:

- MaaS aggregates all the mobility services available in the city, and provides integrated ticketing and payment systems;

- MaaS offers on-demand customised multimodal solutions based on personal transport requirements;

- MaaS is supplied to travellers through a single digital interface.

The small but rising scientific literature on MaaS mainly examines the notion and on-going schemes, as well as its urban challenges, impacts and opportunities. However, almost no research has explored MaaS from the travellers' perspective. Understanding travellers' expectations is essential for designing successful MaaS solutions due to the user-centric approach of the concept. "Transport is redefining itself as mobility and is centred around the customer rather than as a provision to the customer" (Aapaoja et al., 2017).

This research proposes to evaluate travellers' willingness to adopt MaaS solutions that promote the shift towards more sustainable travel behaviours. It aims to identify potential market segments through the recognition of diverse stereotype groups of travellers. For this purpose, we investigate the influence of different types of personal factors (sociodemographic characteristics, personality traits and personal attitudes) on the use of multimodal travel-planners.

\section{Methodology: Survey Design}

The methodological approach proposes to conduct an online survey in the metropolitan area of Madrid (Spain). The questionnaire contains four sections: (i) socio-demographic characteristics, (ii) personal traits, (iii) personal attitudes and (iv) travel habits.

The first section of the survey captures information on typical socio-demographics, including age, gender, education level, employment type, household size, number of people in household under 18, number of cars accessible, number of bikes accessible, owning a driver's license, being able to bike, and having a disability. In the second section, the survey presents a 15 item version of the Big Five Model, called the 
BFI-2-XS ${ }^{1}$, as described in Soto and John (2017). Each of the 15 items measures a specific facet trait: social engagement, assertiveness, energy level, compassion, respectfulness, acceptance of others, organization, productiveness, responsibility, anxiety, depression, emotional volatility, aesthetic sensitivity, intellectual curiosity and creative imagination. The 15 manifest variables constitute the score of five bipolar personality trait constructs, which are Openness (to experience), Conscientiousness, Extroversion, Agreeableness, and Neuroticism. The questions are in the typical form of 'In general, I am someone who...', followed by the 15 statements, for example '...tends to be quiet'. The statements must be scored on a 5 point Likert scale. The third section includes 24 attitudinal statements on a five-points Likert-type scale. They are chosen based on a literature review (Redmond, 2000; Outwater et al., 2003; Ory \& Mokhtarian, 2005; Vredin Johansson et al., 2006; Shiftan et al., 2008; Cools et al., 2009; Lai \& Chen, 2011; Vij \& Walker, 2016; Alonso González et al., 2018) and the relevance for this study. The statements are grouped to define 8 attitudinal factors: openness to experience, need for flexibility, control use of time, need for reliability, need for control, sensitivity to privacy, desire to help the environment and sensitivity to stress. Finally, the last section characterises the most frequent trip of each traveller by asking about this trip's purpose, mode (chain) choice, walking time, frequency, origin and destination.

An exploratory analysis of the data collected allows to identify potential users of the MaaS travel-assistance application. To achieve a representative sample, its distribution must be controlled for gender, age and the frequency of public transport (PT) use.

\section{APPLICATION TO MADRID METROPOLITAN AREA}

The survey was conducted online in February 2019 to collect quantitative data from 1.000 travellers in the metropolitan area of Madrid (Spain).

Madrid was selected as a case study for its dense, highly integrated and well-structured public transport system, which has been recently complemented by the implementation of diverse shared-mobility services (e.g. car, scooter and bike sharing). Several trip-planning tools are currently available in Madrid: HERE Maps, Moovit, CityMapper, OpenStreetMap, Chipi, Google Maps and Mi Transporte. However, none of these applications includes payment or e-ticketing integration.

The Madrid region covers 8,000 km2 divided into 179 municipalities, and it has some 6.4 million inhabitants. It is structured in rings. Madrid is the main city and it is located at the centre of the Region (called zone A), with a population of over 3 million. The metropolitan ring (called inner ring or zone B) encompasses the city of Madrid. The outer ring (called zone $\mathrm{C}$ ) includes the rest of the region with small and medium-sized municipalities.

Mobility patterns in Madrid are properly balanced. There are some 12.9 million trips every working day, with an average trip distance of $6 \mathrm{~km}$ and 29 minutes. The mode share is $40.4 \%$ trips by car, $28.4 \%$ by public transport, $29.9 \%$ on foot and $0.5 \%$ by bike; and $9 \%$ of PT trips are intermodal (Monzon et al., 2016).

\section{RESUlTS AND DISCUSSION}

The survey involved a total of 1.000 respondents from the metropolitan area of Madrid (Spain). The sample was controlled for gender, age and the frequency of public transport use. It is worth mentioning that the most limiting group to be targeted in order to achieve a representative sample were senior travellers ( $>65$ years old), as they are less keen on technology use.

TABLE I. CHARACTERISTICS OF THE SAMPLE

\begin{tabular}{|c|c|c|c|c|c|}
\hline \multicolumn{2}{|c|}{ Age (years old) ${ }^{1}$} & Car license & \multicolumn{3}{|l|}{ Gender } \\
\hline \multirow{2}{*}{$<25$} & \multirow{2}{*}{$10.9 \%$} & \multirow{2}{*}{$52.3 \%$} & \multicolumn{2}{|l|}{ Men } & $37.6 \%$ \\
\hline & & & \multicolumn{2}{|l|}{ Women } & $62.4 \%$ \\
\hline \multirow{2}{*}{$25-34$} & \multirow{2}{*}{$16.4 \%$} & \multirow{2}{*}{$82.9 \%$} & \multicolumn{2}{|l|}{ Men } & $55.5 \%$ \\
\hline & & & \multicolumn{2}{|l|}{ Women } & $44.5 \%$ \\
\hline \multirow{2}{*}{$35-44$} & \multirow{2}{*}{$21.6 \%$} & \multirow{2}{*}{$87.0 \%$} & \multicolumn{2}{|l|}{ Men } & $53.7 \%$ \\
\hline & & & \multicolumn{2}{|l|}{ Women } & $46.3 \%$ \\
\hline \multirow{2}{*}{$45-54$} & \multirow{2}{*}{$21.6 \%$} & \multirow{2}{*}{$88.4 \%$} & \multicolumn{2}{|l|}{ Men } & $50.9 \%$ \\
\hline & & & \multicolumn{2}{|l|}{ Women } & $49.1 \%$ \\
\hline \multirow{2}{*}{$55-64$} & \multirow{2}{*}{$21.6 \%$} & \multirow{2}{*}{$75.0 \%$} & \multicolumn{2}{|l|}{ Men } & $45.4 \%$ \\
\hline & & & \multicolumn{2}{|l|}{ Women } & $54.6 \%$ \\
\hline \multirow{2}{*}{$>65^{a}$} & \multirow{2}{*}{$7.9 \%$} & \multirow{2}{*}{$64.6 \%$} & \multicolumn{2}{|l|}{ Men } & $55.7 \%$ \\
\hline & & & \multicolumn{2}{|l|}{ Women } & $44.3 \%$ \\
\hline \multicolumn{3}{|c|}{ Frequency of use } & PT & Car-S $^{\text {b }}$ & Bike-S $^{\text {c }}$ \\
\hline \multicolumn{3}{|c|}{ At least 4 days a week } & $60.1 \%$ & $3.3 \%$ & $3.7 \%$ \\
\hline \multicolumn{3}{|c|}{ At least once a week } & $23.6 \%$ & $12.6 \%$ & $9.8 \%$ \\
\hline \multicolumn{3}{|c|}{ At least once a month } & $9.8 \%$ & $17.0 \%$ & $11.5 \%$ \\
\hline At least & e a year & & $4.3 \%$ & $9.0 \%$ & $7.9 \%$ \\
\hline Never & & & $2.2 \%$ & $37.1 \%$ & $48.2 \%$ \\
\hline Never an & ever hear & of it & - & $21.0 \%$ & $18.9 \%$ \\
\hline
\end{tabular}

With the objective to evaluate to what extent travellers are comfortable regarding travel-planning applications, they were asked about the frequency of use of these tools for their daily mobility choices. $11.7 \%$ of the respondents never or almost never use these applications; $26.2 \%$, sometimes; and $42.5 \%$, usually. $19.6 \%$ of the respondents declared that they "always use travel and route information services to get information about their trips". Travellers were also asked about their level of reliability on those applications. $5.1 \%$ of the respondents never or almost never rely on these applications; $22.8 \%$, sometimes; and $53.4 \%$, usually. $18.7 \%$ of the respondents always trust on these multimodal tools. Our findings show that the level of use and reliability are directly correlated.

Men and women did not show significant differences regarding the use of travel-planners. Age was negatively and significantly correlated with the adoption of such tools.

FIGURE I. FREQUENCY OF USE: TRAVEL-PLANNERS (AGE)

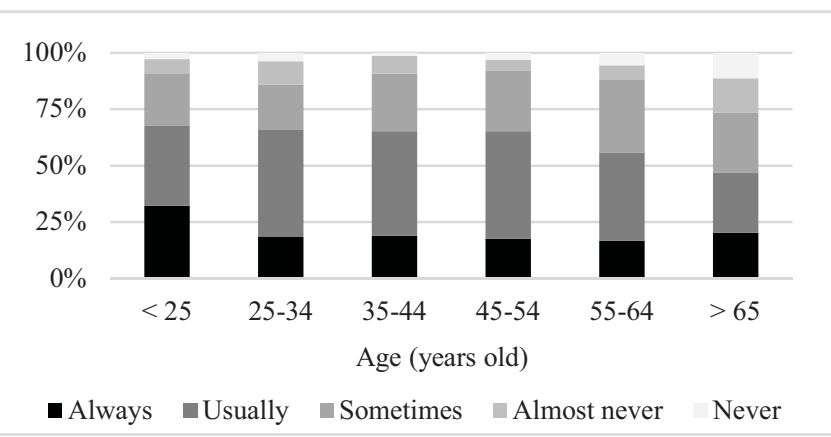

${ }^{1}$ We use the Spanish translation of David Gallardo-Pujol. 
Multimodal travellers showed a higher use of travelplanning applications than unimodal ones for their most frequent trip. $71 \%$ of the multimodal travellers indicated that they "always/usually use travel and route information services to get information about their trip". Only $55 \%$ of the unimodal respondents agreed with that statement. The level of reliability was also higher for multimodal travellers. $77 \%$ and $68.6 \%$ respectively of multimodal and unimodal travellers sustained that "travel and route information services always/usually provide reliable information".

FIGURE II. MUlTIMODAL/UNIMOdAL MOST FreQUENT TRIP AND CAR License Availability (AGE)

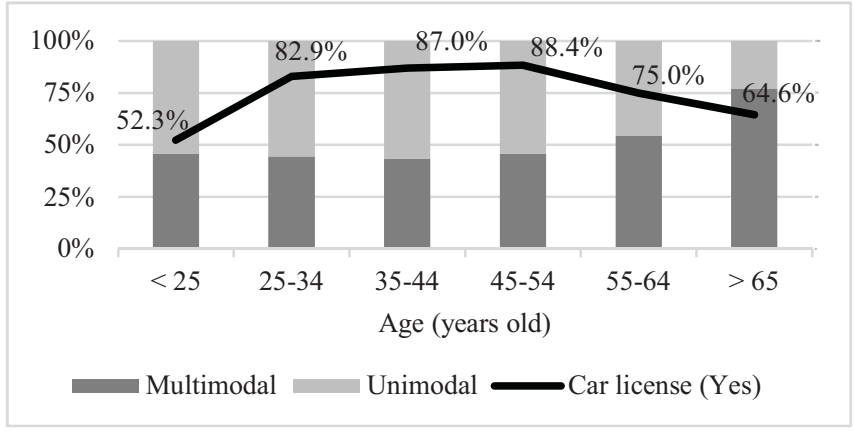

The use of travel-planning applications was lower for the respondents who live in Madrid City than for the ones from the metropolitan area. The same happened with the level of reliability. $17.5 \%$ of the travellers from the urban core declared that they "always use travel and route information services to get information about their trip" and 15.6\% agreed that "travel and route information services always provide reliable information". On the other hand, $30.5 \%$ of the travellers from the metropolitan area stated that they "always use travel and route information services to get information about their trip" and 34.8\% indicated that "travel and route information services always provide reliable information". Again, the level of use and reliability are directly correlated.

Our findings point out that the use of travel-planning applications is positively and significantly correlated with the level of technophilia. Diverse studies sustain that technophilia has found to be more manifested among men, young generations, people with higher education and individuals who frequently use the Internet for travel information. The use of such applications is also positively correlated with the willingness to uptake shared-mobility services (e.g. carsharing or bike-sharing). Kenyon and Lyons (2003) sustain that older generations do not generally consider non-habitual modes for most of their daily trips.

FIGURE III. LEVEL OF TECNOPHILIA: "I LIKE TO TRY NEW WAYS OF TRAVELLING LIKE BIKE OR CAR SHARING” (AGE)

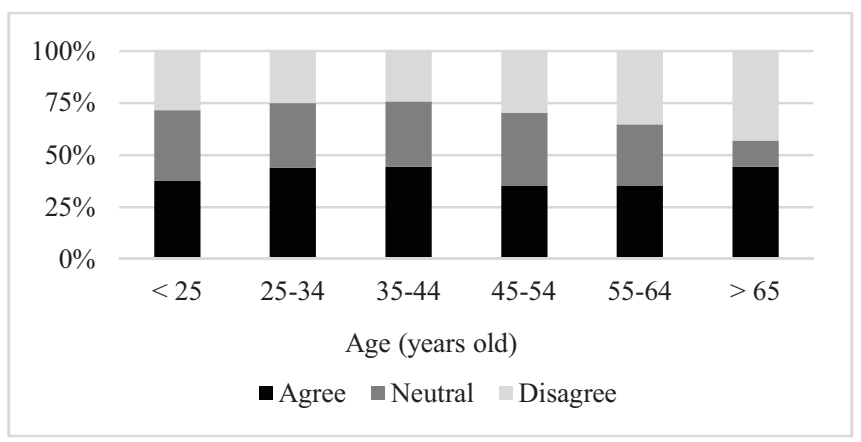

The results also show that the use of multimodal mobility applications is directly correlated with the following attitudinal factors: openness to experience, need for flexibility, control use of time, need for reliability and need for control. Attitudes towards travel are useful for identifying distinct market segments in order to best serve the needs of each group, and to develop strategies for encouraging more sustainable behaviours.

\section{CONCLusions}

The objective of this study is to recognise potential users of a MaaS travel-assistance application, as a step in the process of promoting the adoption of these multimodal tools.

According to our results, age, multimodal travel behaviours, the place of residence and the level of technophilia are factors that impact travellers' willingness to adopt MaaS tools. Attitudinal factors such as openness to experience, need for flexibility, control use of time, need for reliability and need for control also affect significantly the uptake of these solutions.

Many experts have suggested that MaaS provides an opportunity to change the way we live and move in our cities, by encouraging citizens to adopt multimodal mobility behaviours and take more informed choices. MaaS technology is already here. However, it seems not enough. Described as a socio-technical phenomenon, MaaS should be linked with a cultural transition guided by the motivation of share.

The potential of MaaS tools depends deeply on the willingness of travellers to accept and adopt these innovative solutions (Giesecke et al., 2016). Hence understanding users' expectations and preferences is a core requirement for their success.

Overall, the study provides researchers and practitioners with a better understanding of the use of travel-planning applications, allowing to identify potential elements to be considered for the development and implementation of these technologies.

\section{ACKNOWLEDGMENT}

This research has been conducted as part of KLIMATe (marKet potentiaL for a green multIModAl decision supporT e-tool), a European project funded by the EIT Climate KIC (https://eit.europa.eu/).

The authors would like to thank the Universidad Politécnica de Madrid (UPM) for its support through the Programa Propio de I+D+i.

\section{REFERENCES}

[1] Aapaoja, A., Eckhardt, J., Nykänen, L., and Sochor, J., (2017). MaaS service combinations for different geographical areas. Paper Presented at the 24th World Congress on Intelligent Transportation Systems, Montreal, Canada.

[2] Alonso González, M. J., Durand, A., Harms, L., van Oort, N., Cats, O., Hoogendoorn-Lanser, S., and Hoogendoorn, S. P., (2018). Will car users change their mobility patterns with Mobility as a Service (MaaS) and microtransit?--A latent class cluster analysis, 7th Symposium of the European Association for Research in Transportation (hEART).

[3] Cools, M., Moons, E., Janssens, B., and Wets, G., (2009). Shifting towards environment-friendly modes: profiling travelers using Qmethodology. Transportation, 36(4), 437-453. doi: 10.1007/s11116009-9206-Z.

[4] Giesecke, R., Surakka, T., and Hakonen, M. (2016). Conceptualising Mobility as a Service. A user centric view on key issues of mobility 
services. Eleventh International Conference on Ecological Vehicles and Renewable Energies (EVER), Monte Carlo, Monaco.

[5] Hietanen, S. (2014). "Mobility as a Service"-The new transport model? Eurotransport, 12(1), 2-4.

[6] Jin, S. T., Kong, H., Wu, R., and Sui, D. Z. (2018). Ride-sourcing, the sharing economy, and the future of cities. Cities, 76, 96-104. doi:10.1016/J.CITIES.2018.01.012.

[7] Kamargianni, M., Li, W., Matyas, M., and Schäfer, A. (2016). A Critical Review of New Mobility Services for Urban Transport. Transportation Research Procedia, 14, 3294-3303. doi:10.1016/j.trpro.2016.05.277.

[8] Kenyon, S., and Lyons, G., (2003). The value of integrated multimodal traveller information and its potential contribution to modal change. Transportation Research Part F: Traffic Psychology and Behaviour, 6(1), 1-21. doi:10.1016/S1369-8478(02)00035-9.

[9] Lai, W. T. and Chen, C. F., (2011). Behavioral intentions of public transit passengers- The roles of service quality, perceived value, satisfaction and involvement, Transport Policy, 18(2), 318-325. doi: 10.1016/j.tranpol.2010.09.003.

[10] Monzon, A., Cascajo, R., Diaz, M. L., and Barberan, A. (2016). Informe 2014 del Observatorio de la Movilidad Metropolitana. Madrid.

[11] Ory, D. T. and Mokhtarian, P. L., (2005). When is getting there half the fun? Modeling the liking for travel, Transportation Research Part A: Policy and Practice, 39, 97-123. doi: 10.1016/j.tra.2004.09.006.

[12] Outwater, M., Castleberry, S., Shiftan, Y., Ben-Akiva, M., Shuang Zhou, Y., and Kuppam, A., (2003). Attitudinal Market Segmentation Approach to Mode Choice and Ridership Forecasting: Structural Equation Modeling, Transportation Research Record: Journal of the Transportation Research Board, 1854, 32-42. doi: 10.3141/1854-04.

[13] Polis (2017). Mobility as a Service: Implications for urban and regional transport. Discussion paper offering the perspective of Polis member cities and regions on Mobility as a Service (MaaS). Edited by Polis Traffic Efficiency \& Mobility Working Group; Brussels, Belgium.

[14] Redmond, L. S., (2000). Identifying and Analyzing Travel-related Attitudinal, Personality, and Lifestyle Clusters in the San Francisco Bay Area. doi: 10.1002/pmh.1408.

[15] Shiftan, Y., Outwater, M. L. and Zhou, Y., (2008). Transit market research using structural equation modeling and attitudinal market segmentation, Transport Policy, 15(3), 186-195. doi: 10.1016/ j.tranpol.2008.03.002.

[16] Soto, C. J. and John, O. P., (2017). Short and extra-short forms of the Big Five Inventory-2: The BFI-2-S and BFI-2-XS, Journal of Research in Personality, 68, 69-81. doi: 10.1016/j.jrp.2017.02.004.

[17] Vij, A. and Walker, J. L., (2016). How, when and why integrated choice and latent variable models are latently useful, Transportation Research Part B: Methodological, 90, 192-217. doi: 10.1016/j.trb.2016.04.021.

[18] Vredin Johansson, M., Heldt, T. and Johansson, P., (2006). The effects of attitudes and personality traits on mode choice, Transportation Research Part A: Policy and Practice, 40(6), 507-525. doi: 10.1016/j.tra.2005.09.001. 